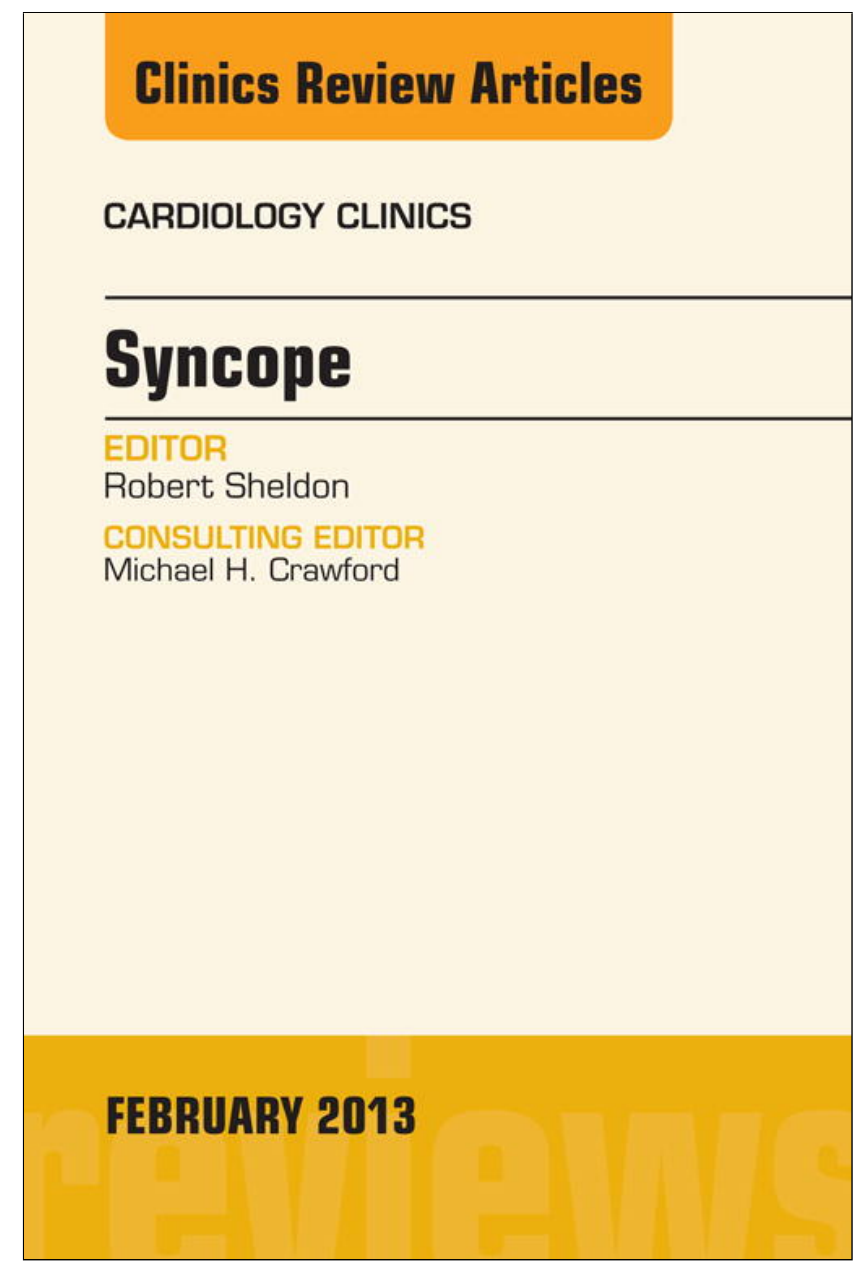

This article appeared in a journal published by Elsevier. The attached copy is furnished to the author for internal non-commercial research and education use, including for instruction at the authors institution and sharing with colleagues.

Other uses, including reproduction and distribution, or selling or licensing copies, or posting to personal, institutional or third party websites are prohibited.

In most cases authors are permitted to post their version of the article (e.g. in Word or Tex form) to their personal website or institutional repository. Authors requiring further information regarding Elsevier's archiving and manuscript policies are encouraged to visit:

http://www.elsevier.com/copyright 


\title{
Syncope Risk Stratification in the Emergency Department
}

\author{
Giorgio Costantino, $\mathrm{MD}^{\mathrm{a}, *}$, Raffaello Furlan, $M D^{\mathrm{b}}$
}

\section{KEYWORDS}

- Syncope $\bullet$ T-LoC $\bullet$ Risk stratification $\bullet$ Rule $\bullet$ Score $\bullet$ Emergency department

\section{KEY POINTS}

- Identify syncope through a detailed history (whenever this is not feasible, any presumed transient loss of consciousness should be considered and managed as syncope).

- Rule out syncope causes that may lead to a rapid clinical deterioration.

- Stratify patients according to risk (clinical judgment, a risk score, or a rule can be used). It is advisable to use the proposed criteria rather than a single anecdotal rule or risk score.

- Use monitoring procedures before deciding on hospitalization.

- Restrict the use of biomarkers to limited and specific cases.

\section{CASE HISTORY}

An 89-year-old woman was seen at the emergency department (ED) complaining of a transient loss of consciousness. Her daughter reported that she suddenly felt as though she were going to die and then suddenly passed out; consciousness was regained after what was described as an endless time, whereas weakness, lightheadedness, and nausea endured for several hours. No additional symptoms, including chest pain and dyspnea, were reported. Physical examination was normal apart from a known cardiac systolic murmur. The electrocardiogram (ECG) confirmed a previously known atrial fibrillation with a ventricular rate of 80 beats per minute. Blood pressure was $130 / 80 \mathrm{~mm} \mathrm{Hg}$. Laboratory tests were within the normal range. Her past history was characterized by arterial hypertension, depression, and a stroke, with the stroke resulting in some memory deficit. She was on warfarin, enalapril, and citalopram.
During the previous 2 weeks, she had been to the ED twice. The first time she was evaluated because of a near syncope while seating after dinner and, 1 week later, a sudden episode with near-syncope symptoms prompted her to go the ED. On both occasions, after a brief observation, she was discharged from the ED with a diagnosis of anxiety.

What steps should be taken to deal with a patient presenting at the ED because of a transient loss of consciousness?

\section{THE FIRST STEP: IDENTIFYING PATIENTS WITH SYNCOPE}

To identify the patient with syncope, 3 major issues have to be addressed:

- Distinguish patients with syncope from those with a transient loss of consciousness (T-LoC) of nonsyncopal origin

- Differentiate patients with syncope from those having falls

- Determine how to manage patients presenting with near syncope

The authors have nothing to disclose.

a Unità Operativa di Medicina Interna II, Dipartimento di Scienze Cliniche "L. Sacco," Ospedale L. Sacco, Università degli Studi di Milano, Via GB Grassi 74, Milano 20157, Italy; b Unità Operativa di Clinica Medica, Humanitas Clinical and Research Center, Università degli Studi di Milano, Via Manzoni 56, Rozzano 20089, Milan, Italy

* Corresponding author.

E-mail address: giorgic@libero.it 


\section{Distinguish Patients with Syncope from Those with a T-LOC of Nonsyncopal Origin}

Syncope is defined by the European Society of Cardiology (ESC) guidelines as a T-LoC caused by transient global cerebral hypoperfusion characterized by rapid onset, short duration, and spontaneous complete recovery. ${ }^{1}$ Therefore, syncope must be differentiated from those situations in which T-LoC is not induced by a global cerebral hypoperfusion, as it is in the case of epilepsy, hypoglycemia, stroke, and carbon monoxide intoxication.

This pathophysiologic definition is important for diagnostic and therapeutic purposes, but it is of limited use in daily clinical practice because cerebral blood flow cannot be quantified during syncope in every patient. Moreover, until a definitive diagnosis is made, it is impossible to identify the pathophysiologic mechanism underlying an undetermined syncope, which accounts for up to $40 \%$ of all events. ${ }^{1,2}$

In keeping with a recent consensus study by Sun and colleagues, ${ }^{3}$ we suggest a practical approach that defines as syncope all T-LoC of presumptive syncopal origin.

\section{Differentiate Patients with Syncope from Those Having Falls}

In clinical practice, it is often impossible to differentiate syncope and falls. Consider the case of an 82-year-old woman who lives alone and is found in the morning by her son on the floor, having likely been there since the evening before. Given that patients are seldom aware of their transient loss of consciousness, in the absence of a witness there is no way to discriminate between a loss of consciousness caused by syncope and one induced by a fall. This concept highlights the crucial role played by a careful history taken from a witness in facilitating the diagnosis during the early evaluation in the ED.

In keeping with these considerations, whenever it is impossible to discriminate between syncope and fall, any T-LoC should initially be considered and managed as syncope, because of its potential adverse outcome. Thereafter the patient should enter the risk stratification process followed by a careful cost benefits evaluation. This latter must always be done before any therapeutic option is started, particularly when potential significant side effects may take place, such as in the case of pacemaker or implantable cardioverter-defibrillator (ICD) implants.

\section{Determine how to Manage Patients Presenting with Near Syncope (Presyncope)}

At present, the management of patients with presyncope is largely heterogeneous worldwide. ${ }^{3,4}$

Presyncope (or near syncope) refers to the feeling of impending LoC without losing consciousness. Several symptoms and physical signs contribute to this subjective feeling, including weakness, lightheadedness, tunnel vision, dizziness, nausea, sweating, and pallor.

Because near syncope can be an indistinct condition and because it is often assumed that its prognosis is better than that of syncope, many studies on syncope performed in the ED excluded patients with presyncope at enrollment. ${ }^{5-7}$ In contrast, other investigators ${ }^{8}$ assumed that syncope and near syncope were identical. To answer this question, Grossman and colleagues ${ }^{4}$ compared the clinical outcome of patients with presyncope with that of individuals with syncope and found no difference. The investigators concluded that the prognosis of near syncope was similar to that of syncope, but this statement has been questioned $^{9-11}$ and data are not available from which to draw definitive conclusions.

Based on these considerations and on the lack of evidence, a physician should judge case by case whether a presyncope episode ought to be considered as a syncope.

It cannot directly be concluded that the 89-year-old patient discussed earlier has syncope (according to the ESC definition, a T-LoC caused by a global cerebral hypoperfusion). That episode can be considered a T-LoC of presumptive syncopal origin, and the patient's past history had no diabetes or epilepsy to suggest a T-LoC of nonsyncopal origin. She did not fall, because the daughter ruled out this possibility. In addition, in our opinion, in the presence of risk factors (age, sudden syncope without preliminary symptoms, abnormal ECG), the 2 previous presyncope episodes should be regarded as syncope.

\section{THE SECOND STEP: RULING OUT CAUSES OF SYNCOPE THAT MAY LEAD TO A RAPID CLINICAL DETERIORATION}

The overall risk for a patient entering the ED because of syncope is between $5 \%$ and $15 \%$, and the mortality at 1 week is about $1 \% .^{5,7,8,10,11}$ The primary goal of the ED physician is thus to discriminate individuals at low risk who can be safely discharged, from patients at high risk who require prompt hospitalization for monitoring and/or appropriate treatment. 
Once a subject has been identified as having had syncope, the diseases potentially leading to a rapid clinical deterioration should be ruled out (Box 1). See the articles as discussed by Krahn and colleagues elsewhere in this issue.

\section{THE THIRD STEP: STRATIFYING THE PATIENT WITH SYNCOPE ACCORDING TO RISK}

Undetermined syncope is common after the first assessment in the ED. Thus, in the absence of a positive diagnosis, the doctor's main goal should shift from the effort to further identify a syncope

\section{Box 1 syncope \\ Cardiovascular \\ Arrhythmias \\ - Ventricular tachycardia degree heart block origin \\ - Long QT syndrome \\ - Brugada syndrome \\ Ischemia}

Potential life-threatening disorders leading to

- Bradycardia: Mobitz type II or third-

- Significant sinus pause (>3 seconds)

ECG features that can suggest an arrhythmic

- Acute coronary syndrome, myocardial infarction

Structural abnormalities

- Valvular heart disease: aortic stenosis, mitral stenosis

- Cardiomyopathy (ischemic, dilated, hypertrophic)

- Atrial myxoma

- Cardiac tamponade

- Aortic dissection

Significant hemorrhage

- Trauma with significant blood loss

- Gastrointestinal bleeding

- Tissue rupture: aortic aneurysm, spleen, ovarian cyst, ectopic pregnancy

- Retroperitoneal hemorrhage

Pulmonary embolism

- Saddle embolus resulting in outflow tract obstruction or severe hypoxia

Subarachnoid hemorrhage cause to an attempt to stratify the patient risk. This stratification can be done from the patient's history and the characteristics of the syncope. Risk stratification can be obtained from clinical experience (clinical judgment) or by using appropriate rules or risk scores. Rules or risk scores may help the ED physician in decision making, although so far there is no compelling evidence that any score or rule performs better than personal clinical judgment in affecting patients' clinical outcomes. ${ }^{10-14}$

\section{Rules}

Rules were developed to stratify the risks of a single patient presenting for syncope in the ED. Most rules were obtained and derived in the ED setting and are intended to assess short-term outcomes. Rules encompass the presence or absence of different dichotomous variables as risk factors. If a single variable is present, then the patient is stratified as high risk and requiring hospital admission.

Examples of such rules are the risk stratification of syncope in the emergency department (Rose), San Francisco Syncope Rule (SFSR), and Boston Syncope Rules, ${ }^{7,8,15}$ with the SFSR ${ }^{8}$ being the only rules that are externally validated.

\section{SFSR}

The SFSR was first published in 2004 by Quinn and colleagues $^{8}$ based on 684 subjects seen for syncope or near syncope in the ED. The investigators found that the presence of any of the variables summarized in Table 1 had a sensitivity of $96 \%$ (95\% confidence interval $[\mathrm{Cl}]$ 92\%-100\%) and a specificity of $62 \%(95 \% \mathrm{Cl} 58 \%-66 \%)$ for predicting adverse events at 1-week follow-up. Death, myocardial infarction, arrhythmia, pulmonary embolism, stroke, subarachnoid hemorrhage, significant hemorrhage, or any condition causing or likely to cause a new clinical evaluation at ED or a new hospitalization for a related event were considered adverse events. The SFSR has been validated by the same investigators in a separate cohort of 791 patients, obtaining a sensitivity of $98 \%(95 \% \mathrm{Cl} 89 \%-100 \%)$ and a specificity of $56 \%(95 \%$ Cl 52\%-60\%) for adverse events at 30-day follow-up. ${ }^{16}$ The use of this rule would have resulted in a $7 \%$ potential reduction of hospital admissions (Tables 2 and $\mathbf{3}$ ).

Since its first reports, the SFSR has been externally validated by other investigators, with discordant results. ${ }^{10,17-19}$ These inconsistencies might be related to the heterogeneous ECG interpretation characterizing those studies. ${ }^{10}$ For example, Quinn and colleagues ${ }^{20,21}$ considered as an abnormal ECG any new alteration, including the 


\begin{tabular}{|c|c|c|c|}
\hline Rule/Score & Acronym & Variables & How Does It Work? \\
\hline SFSR & CHESS & $\begin{array}{l}\text { Congestive heart failure, history of: } \\
\text { Hematocrit }<30 \% \\
\text { ECG, abnormal } \\
\text { Shortness of breath } \\
\text { Systolic blood pressure at triage }<90 \mathrm{~mm} \mathrm{Hg}\end{array}$ & $\begin{array}{l}\text { Patient at high risk if a single } \\
\text { variable is present }\end{array}$ \\
\hline Rose & BRACES & $\begin{array}{l}\text { BNP level } \geq 300 \mathrm{pg} / \mathrm{mL} \text { or bradycardia } \leq 50 \text { in } \\
\text { ED or before hospital } \\
\text { Rectal examination showing fecal occult } \\
\text { blood (if suspicion of gastrointestinal } \\
\text { bleeding) } \\
\text { Anemia: hemoglobin } \leq 90 \mathrm{~g} / \mathrm{L} \\
\text { Chest pain } \\
\text { ECG showing Q wave (not in lead III) } \\
\text { Saturation } \leq 94 \% \text { on room air }\end{array}$ & $\begin{array}{l}\text { Patient at high risk if a single } \\
\text { variable is present }\end{array}$ \\
\hline BOSTON $^{a}$ & None & $\begin{array}{l}\text { I. Signs and symptoms of acute coronary } \\
\text { syndrome } \\
\text { II. Worrisome cardiac history } \\
\text { III. Family history of sudden death } \\
\text { IV. Valvular heart disease } \\
\text { V. Signs of conduction disease } \\
\text { VI. Volume depletion } \\
\text { VII. Persistent ( }>15 \mathrm{~min}) \text { abnormal vital } \\
\text { signs in the ED without the need for } \\
\text { concurrent intervention such as } \\
\text { oxygen, pressor drugs, temporary } \\
\text { pacemakers } \\
\text { VIII. CNS }\end{array}$ & $\begin{array}{l}\text { Patient at high risk if a single } \\
\text { variable is present }\end{array}$ \\
\hline OESIL & None & $\begin{array}{l}\text { History of cardiovascular disease } \\
\text { Abnormal ECG } \\
\text { Age }>65 \text { y } \\
\text { Absence of prodromal symptoms }\end{array}$ & $\begin{array}{l}\text { Single factor counts as } 1 \text {. } \\
\text { Sum } \leq 1=\text { low risk; } \\
\text { sum }>1=\text { high risk }\end{array}$ \\
\hline EGSYS & None & $\begin{array}{l}\text { Palpitations preceding syncope ( } 4 \text { pts) } \\
\text { Heart disease, abnormal ECG, or both ( } 3 \text { pts) } \\
\text { Syncope during effort ( } 3 \text { pts) } \\
\text { Syncope while supine ( } 2 \text { pts) } \\
\text { Precipitating or predisposing factors, or both } \\
\text { (warm, crowded place/prolonged } \\
\text { orthostasis/fear-pain-emotion) (-1 pts) } \\
\text { Autonomic prodromes (nausea/vomiting) } \\
\text { (-1 pts) }\end{array}$ & $\begin{array}{l}\text { Score } \geq 3 \text { pts is considered } \\
\text { positive }\end{array}$ \\
\hline
\end{tabular}

Abbreviations: BNP, brain natriuretic peptide; EGSYS, Evaluation of Guidelines in Syncope Study; pts, points; OESIL, Osservatorio Epidemiologico sulla Sincope del Lazio; ROSE, Risk Stratification of Syncope in the Emergency Department; SFSR, San Francisco Syncope Rule.

${ }^{a}$ I: 1, complaint of chest pain of possible cardiac origin; 2, ischemic ECG changes (ST increase or deep [>0.1 mV] ST depression); 3, other ECG changes (VT, VF, supraventricular tachycardia [SVT], rapid atrial fibrillation, or new [or not known to be old] ST-T wave changes); 4, complaint of shortness of breath. II: 5, history of coronary artery disease, including deep Q waves and hypertrophic or dilated cardiomyopathy; 6 , history of congestive heart failure or left ventricular dysfunction; 7; history of or current ventricular tachycardia, ventricular fibrillation; 8, history of pacemaker; 9, history of ICD; 10, prehospital use of antidysrhythmic medication excluding $\beta$-blockers or calcium channel blockers. III: 11, family history (first-degree relative) with sudden death, HOCM, Brugada syndrome, or long QT syndrome. IV: 12 , heart murmur noted in history or on ED examination. V: 13, multiple syncopal episodes within the last 6 months; 14, rapid heart beat by patient history; 15, syncope during exercise; 16, QT interval $>500 \mathrm{~ms} ; 17$, second-degree or third-degree heart block or intraventricular block. VI: 18, gastrointestinal bleeding by Hemoccult or history; 19, hematocrit <30; 20, dehydration not corrected in the ED per treating physician discretion. VII: 21, respiratory rate $>24$ breaths $/ \mathrm{min} ; 22, \mathrm{O}_{2}$ saturation $<90 \%$; 23 , sinus rate $<50$ beats/min or sinus rate $>100$ beats $/ \mathrm{min} ; 24$, blood pressure $<90 \mathrm{~mm} \mathrm{Hg}$. VIII: 25 , primary CNS event (ie, SAH, stroke). 
Table 2

Features of the studies leading to a risk stratification tool and its external validation

\begin{tabular}{|c|c|c|c|c|}
\hline $\begin{array}{l}\text { Rule/ } \\
\text { Score } \\
\end{array}$ & $\begin{array}{l}\text { Derivation } \\
\text { Population } \\
\end{array}$ & $\begin{array}{l}\text { Validation } \\
\text { Population } \\
\end{array}$ & Setting; Follow-up & External Validation \\
\hline SFSR & $\begin{array}{l}684 \text { syncope or } \\
\text { near syncope }\end{array}$ & $\begin{array}{l}791 \text { patients with } \\
\text { syncope or near } \\
\text { syncope }\end{array}$ & $\begin{array}{l}\text { ED; derivation } 7 \mathrm{~d} \text {, } \\
\text { validation } 30 \mathrm{~d}\end{array}$ & $\begin{array}{l}\text { Systematic review: } \\
\text { sensitivity } 87 \%(95 \% \\
\text { Cl } 79-93) \text {, and } \\
\text { specificity of } 52 \% \\
(95 \% \mathrm{Cl} 43-62)^{10} \\
\end{array}$ \\
\hline Rose & 550 patients & 550 patients & $E D ; 30 \mathrm{~d}$ & None \\
\hline BOSTON & None & 362 patients & $E D ; 30 \mathrm{~d}$ & None \\
\hline OESIL & $\begin{array}{c}270 \text { patients in EDs, } \\
1 \text {-y follow-up }\end{array}$ & $\begin{array}{l}328 \text { patients, } \\
1-y \text { follow-up }\end{array}$ & ED; 1 y & Few studies ${ }^{12}$ \\
\hline EGSYS & 260 patients & 258 patients & $\begin{array}{l}\text { ED; diagnosis of } \\
\text { cardiac syncope } \\
\text { on a predefined } \\
\text { diagnostic item; } \\
\text { mortality at } 2 y\end{array}$ & None \\
\hline
\end{tabular}

ECG abnormalities observed during a patient's monitoring in the ED. In contrast, other studies focused only on the ECG features obtained at ED presentation. Sacillotto and colleagues ${ }^{10}$ assessed the sensitivity and specificity of that rule by a systematic review and reported a sensitivity of $87 \%(95 \% \mathrm{Cl} 79-93)$ and a specificity of $52 \%$ (95\% Cl 43-62). These investigators concluded that the SFSR can be useful in the decisionmaking process of admitting or discharging patients from the ED for those patients with undetermined syncope after ED evaluation. They concluded that a posttest probability of adverse events lower than $2 \%$ would be suitable to safely discharge patients. However, this conclusion is arbitrary because it does not take into account that the exclusion of the dangerous causes of syncope during the ED stay may reduce the likelihood of adverse events more than the reduction caused by a good performance of the rule. In addition, the SFSR did not provide clues to the clinical features of patients who should undergo continuous cardiovascular and respiratory monitoring.

\section{The Rose rule}

The Rose rule was published in 2010 and was derived and validated in a single ED center in Edimburgh. ${ }^{7}$ Reed and colleagues ${ }^{7}$ recruited 550 patients for deriving and 550 individuals for validating the rule and observed that the presence of at least 1 of the proposed variables (risk factors) had a sensitivity of $87 \%$ and a specificity of $66 \%$ for adverse events (see Tables 1-3). Adverse events included acute myocardial infarction, lifethreatening arrhythmias (ventricular fibrillation, sustained, ventricular tachycardia, ventricular pause $>3$ seconds), pacemaker or cardiac defibrillator implant within 1 month from the index syncope, pulmonary embolism, cerebrovascular accidents, intracranial or subarachnoid hemorrhage, hemorrhage requiring more than 2 units of blood transfusion, acute surgical procedures, or endoscopic intervention (see Table 2).

The limits of this rule are the poor sensitivity found during the internal validation and the need of a laboratory test (ie, B-type natriuretic peptides [BNP]). This latter limitation implies that all patients presenting in the ED for syncope should have bloods taken, thus partially diverging from the ESC syncope guideline suggestions ${ }^{1}$ and everyday clinical practice. Moreover, no external validation of the rule is available at the moment.

\section{The Boston Syncope Rule}

The Boston Syncope Rule was first published in 2007 by Grossman and colleagues. ${ }^{15}$ The investigators recruited 362 patients and considered the variables (risk factors) reported in the American College of Emergency Physicians' clinical policy on syncope. ${ }^{22}$ Given the presence of at least 1 of the variables, the sensitivity and specificity of the rule was 97\% (95\% Cl 93-100) and 62\% (95\% Cl 56-69), respectively (see Tables 1-3).

Its complexity is the major weakness of this rule because more than 10 variables should be considered. In addition, some variables, such as primary central nervous system (CNS) events are adverse events themselves. This weakness does not help physician to decide which patient deserves closer observation, monitoring, or hospital admission, 
Table 3

Adverse events and ECG features taken into account by the different risk stratification tools

$\begin{array}{lll}\text { Rule/Score Anomalous ECG Adverse Events } & \end{array}$
\begin{tabular}{ll}
\hline SFSR & Any new change \\
In the absence of a previous ECG, any \\
abnormality during ECG repetition or
\end{tabular} monitoring

Death, myocardial infarction, arrhythmias, pulmonary embolism, stroke, subarachnoid hemorrhage, significant hemorrhage, or any condition causing or likely to cause a return to ED and hospitalization for a related event

Rose Q wave (not in lead III)

Acute myocardial infarction according to the universal definition, life-threatening arrhythmias (ventricular fibrillation, sustained ventricular tachycardia, ventricular pause $>3 \mathrm{~s}$ ), pacemaker or cardiac defibrillator implant within 1 mo of index collapse, pulmonary embolus, cerebrovascular accident, intracranial hemorrhage, or subarachnoid hemorrhage, hemorrhage requiring a blood transfusion of 2 units, acute surgical procedure, or endoscopic intervention

BOSTON QT interval $>500 \mathrm{~ms}$

Second-degree or third-degree heart block or intraventricular block

Ischemic ECG changes (ST increase or ST depression $[>0.1 \mathrm{mV}])$

Other ECG changes (VT, VF, SVT, rapid atrial fibrillation, or new [or not known to be old] ST), T wave changes, deep Q waves

The sinus rate $<50$ beats/min or sinus rate $>100$ beats $/ \mathrm{min}$
Pacemaker/implantable cardiac defibrillator placement, percutaneous coronary intervention, surgery, blood transfusion, cardiopulmonary resuscitation, alterations in antidysrhythmic therapy, endoscopy with intervention, or correction of carotid stenosis, death, pulmonary embolus, stroke, severe infection/sepsis, ventricular dysrhythmia, atrial dysrhythmia (including SVT and atrial fibrillation with rapid ventricular response), intracranial bleed, hemorrhage, myocardial infarction, cardiac arrest, or life-threatening sequelae of syncope (ie, rhabdomyolysis, long bone or cervical spine fractures)

OESIL Rhythm abnormalities (atrial fibrillation or Death at follow-up flutter, SVT, multifocal atrial tachycardia, frequent or repetitive premature supraventricular or ventricular complexes, sustained or nonsustained ventricular tachycardia, paced rhythms)

Atrioventricular or intraventricular conduction disorders (complete atrioventricular block, Mobitz I or Mobitz II atrioventricular block, bundle branch block or intraventricular conduction delay)

Left or right ventricular hypertrophy; left axis deviation

Old myocardial infarction, ST segment and T wave abnormalities consistent with or possibly related to myocardial ischemia 


\begin{tabular}{|c|c|c|}
\hline Rule/Score & Anomalous ECG & Adverse Events \\
\hline $\begin{array}{l}\text { Evaluation of } \\
\text { Guidelines in } \\
\text { Syncope Study } \\
\text { (EGSYS) }\end{array}$ & $\begin{array}{l}\text { Sinus bradycardia, atrioventricular } \\
\text { block greater than first degree, } \\
\text { bundle branch block } \\
\text { Acute or old myocardial infarction } \\
\text { Supraventricular or ventricular } \\
\text { tachycardia } \\
\text { Left or right ventricular hypertrophy, } \\
\text { ventricular preexcitation long QT, } \\
\text { and Brugada pattern }\end{array}$ & $\begin{array}{l}\text { Diagnosis of cardiac syncope: } \\
\text { Mechanical cardiac syncope (severe } \\
\text { valvular stenosis, or other flow } \\
\text { obstruction, acute myocardial } \\
\text { ischemia) } \\
\text { Arrhythmic syncope (sinus bradycardia, } \\
40 \text { beats/min or repetitive sinoatrial } \\
\text { blocks or sinus pauses of } 3 \mathrm{~s} \text {; Mobitz } 2 \\
\text { or advanced second-degree } \\
\text { atrioventricular block or third-degree } \\
\text { atrioventricular block; alternating } \\
\text { left and right bundle branch block, } \\
\text { pacemaker malfunction with cardiac } \\
\text { pauses, rapid paroxysmal } \\
\text { supraventricular or ventricular } \\
\text { tachyarrhythmias) electrophysiologic } \\
\text { study alterations }\end{array}$ \\
\hline
\end{tabular}

because in the presence of an acute cerebral hemorrhage it is self-evident that hospital admission is mandatory.

\section{Scores}

Although rules consider the presence of a specific variable sufficient to put the patient in a high-risk class, scores incorporate several variables. These variables are combined to derive a score that enables the prediction of the subsequent risk to the patient.

The scores were built up mostly by cardiologists and are typically aimed at identifying cardiac adverse events. This article discusses the Osservatorio Epidemiologico sulla Sincope del Lazio (OESIL) and the EGSYS risk scores.

\section{OESIL risk score}

OESIL was published in $2003^{23}$ based on a derivation cohort in which Colivicchi and colleagues ${ }^{23}$ recruited 270 patients presenting to ED for syncope. The validation cohort was subsequently based on 328 individuals. The data suggested that the presence of anomalous ECG, absence of presyncope symptoms, history of cardiovascular disease, and age older than 65 years were the risk factors associated with a poor prognosis at 1-year follow-up (see Tables 1-3). Later, the OESIL risk score was externally validated using the Short-Term Prognosis of Syncope (STePS) ${ }^{5}$ population and compared with the SFSR by Dipaola and colleagues. ${ }^{12}$ In the work by Dipaola and colleagues, ${ }^{12}$ our group showed that the OESIL risk score had a sensitivity of $88 \%(95 \% \mathrm{Cl}$
70-98) and a specificity of $60 \%$ (95\% Cl 55-64), and the SFSR $81 \%(95 \% \mathrm{Cl} 61-93)$ and $63 \%$ (95\% Cl 58-67), in predicting an adverse outcome within 10 days. The clinical judgment (ie, the doctor's decision to admit or discharge patients from ED independently of any strict adherence to predefined protocol or risk scores) had a sensitivity of $77 \%(95 \% \mathrm{Cl} 56-91)$ and a specificity of $69 \%(95 \% \mathrm{Cl} 64-73)$. The sensitivities of the 3 decision-making approaches were not significantly different, but the SFSR and OESIL would have recognized all 5 patients who died within 10 days from syncope, whereas the clinical judgment missed 2 deaths. However, the numbers of patients and events were inadequate to draw definitive conclusions. Although derived on events at 1 year, the OESIL risk score proved to be useful even in the short-term risk stratification of patients with syncope. Major limitations of OESIL result from the small number of its independent validations, whereas its main strength is its simplicity, which enables its use even by nurses triaging patients with syncope.

\section{EGSYS score}

The EGSYS score was derived and internally validated by Del Rosso and colleagues. ${ }^{6}$ It is the only score that considered as events the different causes of syncope and it was specifically aimed at identifying a cardiac cause of the syncopal episode. The investigators reported that the score is characterized by a sensitivity of $92 \%(95 \% \mathrm{Cl}$ $77-98)$ and specificity of $69 \%$ (95\% Cl 63-75). There are no external validations of such a score, 
particularly in the emergency setting, and, for this reason, the score is likely to be more useful in a cardiologic setting than in the ED, where syncope episodes induced by noncardiac diseases are more frequent (see Tables 1-3).

Table 4 compares the strength and weakness of different rules and scores used for syncope risk stratification.

Let us try to stratify the risk after syncope of the 89-year-old patient discussed earlier, by using the previously mentioned clinical rules and risk scores.

The patient would have been stratified as being at significant risk, thus deserving hospital admission, according to the Rose rule (ECG positive), OESIL risk score (ECG, age), EGSYS score (ECG and cardiovascular history), and Boston (multiple syncope, cardiac systolic murmur). In contrast, at admission in the ED she would have been stratified as being at low risk according to the SFSR. However, her recurrence of syncope, age, and cardiovascular history would make any physician uncomfortable about an early discharge.

To make this evaluation easier for the reader, this article discusses the strengths and limitations of the different rules or risk scores in Table 4.

The hospitalization rates related to syncope vary widely worldwide, ranging from $15 \%$ to $65 \% .^{2}$ This variation may be secondary to the differing organization of health care systems; to the consequent different patients' health care patterns; to the availability of both inpatient and outpatient facilities for prompt syncope diagnosis and therapy, such as those provided by a syncope unit ${ }^{24}$; and to physicians' personal knowledge of this disorder and awareness of guidelines and clinical risk scores.

A recent investigation ${ }^{14}$ emphasized the lack of evidence that syncope decision rules might improve syncope diagnostic accuracy or reduce work-up costs, thus challenging their usefulness. A new tool for syncope management is represented by the syncope unit, ${ }^{24}$ in which differing medical competence and several facilities are functionally combined, as discussed in a dedicated article elsewhere in this issue. Fig. 1 shows a flow diagram of a possible syncope approach in the ED.

Do any of the risk rules or scores identify people who might have adverse outcomes caused by syncope, or do they simply identify people who will have an adverse outcome and happen to have syncope?

Based on our previous observations, ${ }^{5}$ there are 2 clinically important time frames for syncope. The early period (hours and days) following syncope characterized by the largest mortality because of a new and still undiagnosed lifethreatening disorder leading to syncope, and a second period characterized by a time scale of months or years in which comorbidity and frailty play a major role. Because there is a low rate of adverse events following syncope, the risk scores and clinical rules are likely to better identify frailty than patients' short-term risk, which might account for the poor performance of the rule/ scores in identifying short-term adverse clinical outcomes. $^{10-12}$

Based on these considerations, the role of clinical decision rules or risk scores and their comparison with clinical judgment in the management of patients presenting in the ED for syncope remain to be elucidated. In addressing syncope, risk scores and decision rules can be useful by highlighting the critical variables that should be considered and we expect that the international single-patient meta-analysis currently in progress will provide a tentative answer to these issues.

\begin{tabular}{|c|c|c|}
\hline Rule/Score & Strengths & Limitations \\
\hline SFSR & $\begin{array}{l}\text { User friendly } \\
\text { Derived in the ED } \\
\text { All adverse events considered } \\
\text { Several external validations }\end{array}$ & $\begin{array}{l}\text { Inconsistency in validations results } \\
\text { Decision of patients monitoring at physician's } \\
\text { discretion }\end{array}$ \\
\hline Rose & $\begin{array}{l}\text { User friendly } \\
\text { Derived in the ED } \\
\text { All adverse events considered }\end{array}$ & $\begin{array}{l}\text { Need venous sample } \\
\text { Not externally validated } \\
\text { Limited sensitivity compared with other rules }\end{array}$ \\
\hline BOSTON & $\begin{array}{l}\text { Derived in the ED } \\
\text { All adverse events considered }\end{array}$ & $\begin{array}{l}\text { Complicated } \\
\text { Overlap between risk factors and adverse events }\end{array}$ \\
\hline OESIL & User friendly & Not derived in the ED \\
\hline EGSYS & $\begin{array}{l}\text { User friendly } \\
\text { Considered cardiac cause of syncope }\end{array}$ & $\begin{array}{l}\text { Not derived in the ED } \\
\text { Not consider all adverse events }\end{array}$ \\
\hline
\end{tabular}




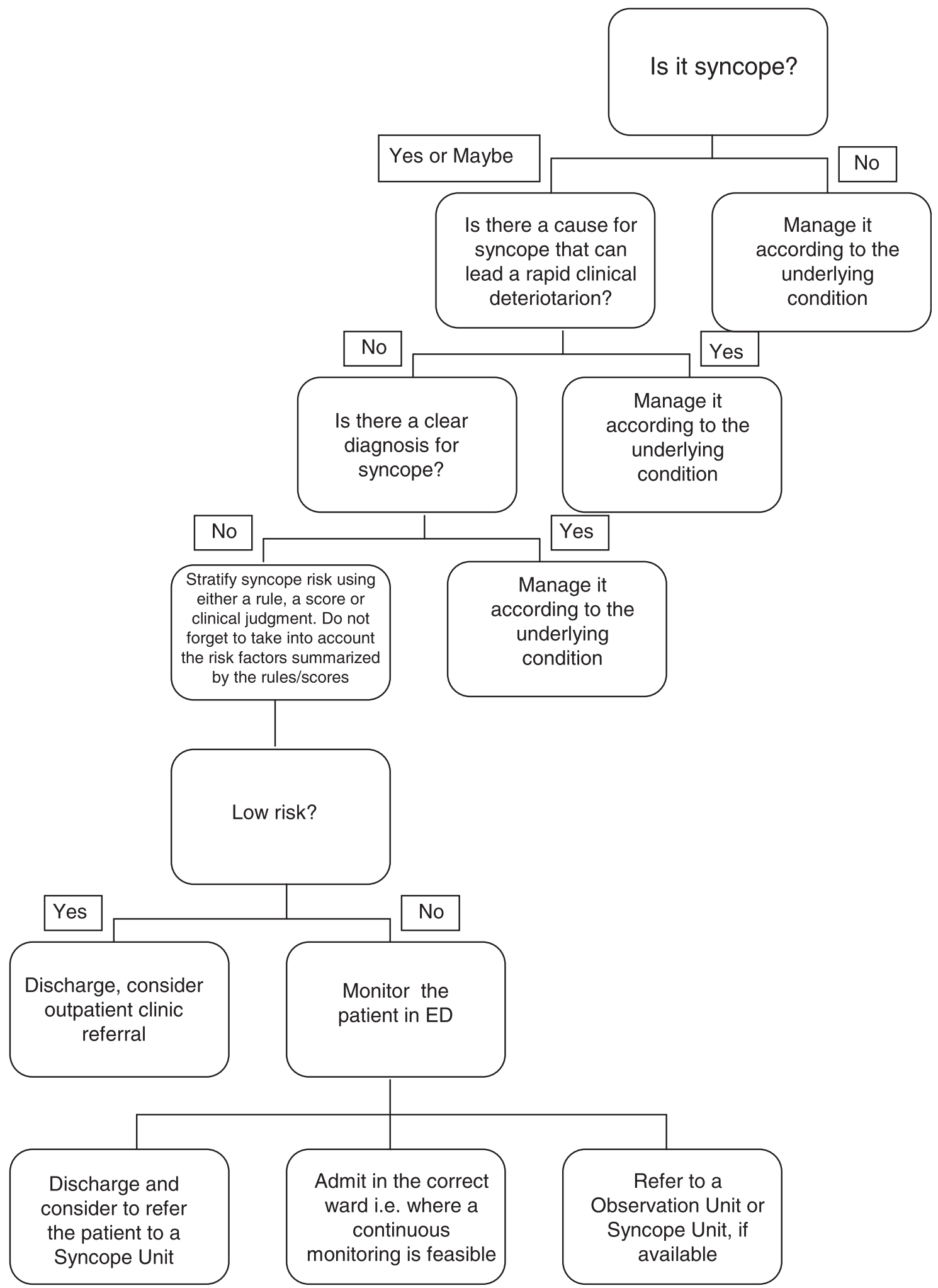

Fig. 1. Syncope diagnostic and risk stratification flow chart.

\section{DOES HOSPITAL ADMISSION AFFECT SYNCOPE PROGNOSIS?}

Difficulties in promptly addressing the cause of syncope in the emergency setting and concerns about fatal arrhythmias and sudden death often lead to an excessive hospital admission rate, with increasing costs. ${ }^{2}$ For this reason, whether or not hospital admission significantly affects the outcome is an important issue.

The STePS study performed by our group specifically addressed this topic ${ }^{5}$ and included 676 consecutive patients who presented for syncope in 4 EDs. Both short-term (ie, within 10 days) and long-term (ie, within 1 year) adverse events were assessed and compared in admitted 
and discharged patients, and the main variables (risk factors) associated with a poor prognosis within 10 days from syncope were abnormal ECG, concomitant trauma, absence of symptoms of impending syncope, and male sex. Those variables differed from the risk factors associated with adverse prognosis in the long term, which were age older than 65 years, history of neoplasm, cerebrovascular disease, structural heart disease, and ventricular arrhythmia. Although the number of major therapeutic procedures (ie, pacemaker or implantable cardioverter-defibrillator implants, intensive care unit admission, cardiopulmonary resuscitation maneuvers) was significantly higher in admitted than in discharged patients, mortalities were similar in both groups, and all subjects who underwent major procedures could subsequently be discharged. Taken together, these observations suggest that hospital admission may have ameliorated the short-term clinical outcome of patients with syncope, possibly because of the lifesaving measures (ie, the major therapeutic procedures) that could readily be carried out. However, admitted patients had a worse 1-year prognosis compared with their discharged counterparts, possibly secondary to enhanced rates of coexisting conditions (Fig. 2). Thus, in the long term, comorbidities, rather than syncope, play a crucial role in affecting 1-year prognosis. In the long term, syncope could be considered as an expression of the frailty of the patient, which may represent one of the main problems to be faced whenever rules and scores are used for syncope risk stratification. Because of the paucity of deaths and adverse events following syncope in the short term, most of the risk scores and few of the clinical rules have been derived or validated in the middle period (ie, between 30 days and 1 month from the event). Thus, rules are likely to better address the frailty of the patient with syncope, whereas, in the short term, they may be unable to identify patients in whom syncope is the epiphenomenon of a potentially life-threatening disease.

We conclude that hospitalization is definitively useful in patients who need close monitoring or are likely to undergo major therapeutic procedures. Based on the observation that the 48 hours following syncope present the highest risk for death, ${ }^{5}$ continuous cardiorespiratory monitoring for at least 48 hours, rather than a prolonged hospitalization, is likely to favorably affect the prognosis.

\section{WHAT IS THE ACCEPTABLE RISK OF ADVERSE EVENTS IN A DISCHARGED PATIENT WHO HAD SYNCOPE?}

Usefulness of syncope risk stratification as a clinical tool for ED physicians can be evaluated according to 2 different approaches:

1. By comparing syncope risk scales with simple clinical judgment and verifying that the overall performance of a specific risk score is higher than that of the physician decision-making process. Its application may result in safer and more specific clinical management for the patient with syncope.

2. An acceptable risk threshold has to be set. According to clinical rules, major events and death risk have to be addressed in a subject who is about to be discharged from the ED. Thereafter, a clinical rule could be safely used whenever the overall risk is lower than the value of the predefined risk threshold. However, because the risk of death and major clinical events from syncope is low ( $0.7 \%$ and $5.4 \%$, respectively),${ }^{5}$ an

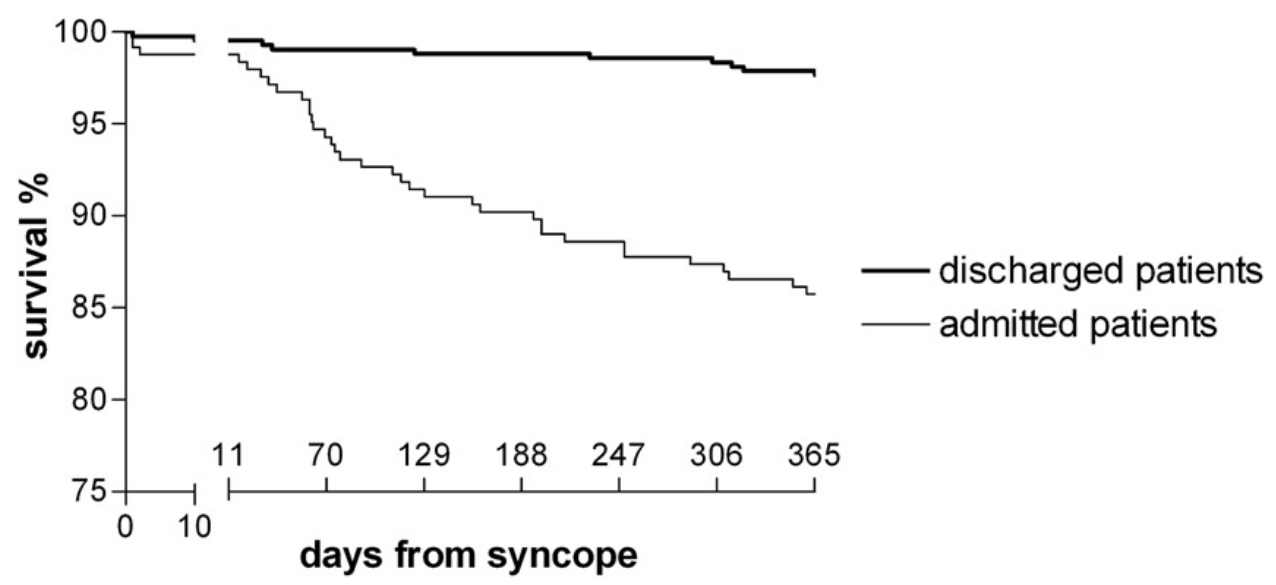

Fig. 2. Survival curves of admitted and discharged patients enrolled in the STePS study. Note that discharged patients had lower long-term mortality than admitted individuals. (Modified from Costantino G, Perego F, Dipaola $F$, et al. Short- and long-term prognosis of syncope, risk factors, and role of hospital admission: results from the STePS (Short-Term Prognosis of Syncope) study. J Am Coll Cardiol 2008;51:276-83; with permission.) 
acceptable risk is hard to define. Moreover, there is no consensus about risk thresholds, and different groups consider different thresholds to be acceptable. ${ }^{10,25}$

\section{ARE LABORATORY BIOMARKERS USEFUL FOR ED CLINICAL DECISION MAKING?}

The European syncope guidelines do not consider routine tests, as assessed by a venous sample, to be appropriate for syncope evaluation in all patients. ${ }^{1}$ However, D-dimer and other biomarkers have attracted interest for risk stratification in the ED.

\section{D-Dimer}

There is evidence that the routine measurement of $\mathrm{D}$-dimer in patients presenting to the ED for syncope is useless both for identifying the cause of syncope and as a prognostic index. ${ }^{26} \mathrm{D}$-dimer may have a significant role in selected syncope cases in which there is significant suspicion for pulmonary embolism or aortic dissection. ${ }^{27}$

\section{Troponin}

There is evidence that routine measurement of troponin is of limited effectiveness in the ED management of the patient with syncope, although it can be useful in selected cases in which acute coronary syndrome is suspected. ${ }^{28}$ There are no conclusive data on the use of ultrasensitive troponin assays.

\section{BNPS}

$\mathrm{N}$-Terminal pro-brain natriuretic peptide (NTproBNP) and BNP have been used to assess the prognosis and cause of syncope. In the Rose decision rule, ${ }^{7}$ the plasma BNP level was proposed as a reliable marker for syncope risk stratification. In addition, BNP was recommended to discriminate cardiac and noncardiac causes of syncope. Increased BNP and NT-proBNP plasma levels have been observed in arrhythmias and these peptides have thus raised interest as biomarkers of arrhythmic syncope. ${ }^{29}$ Pfister and colleagues ${ }^{30}$ suggested the use of NT-proBNP to differentiate arrhythmic from nonarrhythmic syncope. However, a single BNP assessment is largely influenced by comorbidities $^{31}$ and we reported ${ }^{32}$ that the time course of BNP and NT-proBNP changes following an induced ventricular fibrillation had a peak of increase of both biomarkers 9 hours after the event. These data suggested that the use of BNP kinetics, rather than single plasma measurements, could be useful both to identify a potential arrhythmic cause of syncope and for patient risk stratification, but prospective studies are expected to confirm this hypothesis.

The 89-year-old patient discussed earlier felt that she was going to die during ECG continuous monitoring in the ED. The ECG showed a 4-second pause. A permanent pacemaker was placed and, so far, the patient has not had another syncope spell.

\section{ACKNOWLEDGMENTS}

We would like to acknowledge all STePS investigators, and in particular Carlo Selmi, Franca Dipaola, Mattia Bonzi, and Ilaria Bossi, for their valuable comments and suggestions.

\section{REFERENCES}

1. Moya A, Sutton R, Ammirati F, et al. Guidelines for the diagnosis and management of syncope (version 2009). Eur Heart J 2009;30:2631-71.

2. D'Ascenzo F, Biondi-Zoccai G, Reed MJ, et al. Incidence, etiology and predictors of adverse outcomes in 43,315 patients presenting to the emergency department with syncope: an international metaanalysis. Int J Cardiol 2011. [Epub ahead of print].

3. Sun BC, Thiruganasambandamoorthy V, Cruz JD. Standardized reporting guidelines for emergency department syncope risk-stratification research. Acad Emerg Med 2012;19:694-702.

4. Grossman SA, Babineau M, Burke $L$, et al. Do outcomes of near syncope parallel syncope? Am J Emerg Med 2012;30:203-6.

5. Costantino G, Perego F, Dipaola F, et al. Short- and long-term prognosis of syncope, risk factors, and role of hospital admission: results from the STePS (Short-Term Prognosis of Syncope) study. J Am Coll Cardiol 2008;51:276-83.

6. Del Rosso A, Ungar A, Maggi R, et al. Clinical predictors of cardiac syncope at initial evaluation in patients referred urgently to a general hospital: the EGSYS score. Heart 2008;94:1620-6.

7. Reed MJ, Newby DE, Coull AJ, et al. The ROSE (Risk Stratification of Syncope in the Emergency Department) study. J Am Coll Cardiol 2010;55:713-21.

8. Quinn JV, Stiell IG, McDermott DA, et al. Derivation of the San Francisco Syncope Rule to predict patients with short-term serious outcomes. Ann Emerg Med 2004;43:224-32.

9. Cernuschi G, Bonzi M, Fiorelli E, et al. Do outcomes of near syncope parallel syncope? Am J Emerg Med 2012. [Epub ahead of print].

10. Saccilotto RT, Nickel CH, Bucher HC, et al. San Francisco Syncope Rule to predict short-term serious outcomes: a systematic review. CMAJ 2011;183:E1116-26. 
11. Serrano LA, Hess EP, Bellolio MF, et al. Accuracy and quality of clinical decision rules for syncope in the emergency department: a systematic review and meta-analysis. Ann Emerg Med 2010; 56:362-73.

12. Dipaola F, Costantino G, Perego F, et al. San Francisco syncope rule, osservatorio epidemiologico sulla sincope nel lazio risk score, and clinical judgment in the assessment of short-term outcome of syncope. Am J Emerg Med 2010;28:432-9.

13. Perego F, Costantino G, Dipaola F, et al. Predictors of hospital admission after syncope: relationships with clinical risk scores. Int J Cardiol 2012. [Epub ahead of print].

14. Sheldon RS, Morillo CA, Krahn AD, et al. Standardized approaches to the investigation of syncope: Canadian Cardiovascular Society position paper. Can J Cardiol 2011;27:246-53.

15. Grossman SA, Fischer C, Lipsitz LA, et al. Predicting adverse outcomes in syncope. J Emerg Med 2007; 33:233-9.

16. Quinn J, McDermott D, Stiell I, et al. Prospective validation of the San Francisco Syncope Rule to predict patients with serious outcomes. Ann Emerg Med 2006;47:448-54.

17. Sun BC, Mangione CM, Merchant G, et al. External validation of the San Francisco Syncope Rule. Ann Emerg Med 2007;49:420-7.

18. Thiruganasambandamoorthy $V$, Hess EP, Alreesi A, et al. External validation of the San Francisco Syncope Rule in the Canadian setting. Ann Emerg Med 2010;55:464-72.

19. Birnbaum A, Esses D, Bijur P, et al. Failure to validate the San Francisco Syncope Rule in an independent emergency department population. Ann Emerg Med 2008;52:151-9.

20. Quinn J, McDermott D. ECG criteria of the San Francisco Syncope Rule. Ann Emerg Med 2011; 57:72-3.

21. Quinn J, McDermott D. Electrocardiogram findings in emergency department patients with syncope. Acad Emerg Med 2011;18:714-8.
22. American College of Emergency Physicians. Clinical policy: critical issues in the evaluation and management of patients presenting with syncope. Ann Emerg Med 2001;37:771-6.

23. Colivicchi F, Ammirati F, Melina D, et al. Development and prospective validation of a risk stratification system for patients with syncope in the emergency department: the OESIL risk score. Eur Heart J 2003; 24:811-9.

24. Shen WK, Decker WW, Smars PA, et al. Syncope Evaluation in the Emergency Department Study (SEEDS): a multidisciplinary approach to syncope management. Circulation 2004;110:3636-45.

25. McNally M, Curtain J, O'Brien KK, et al. Validity of British Thoracic Society guidance (the CRB-65 rule) for predicting the severity of pneumonia in general practice: systematic review and meta-analysis. Br J Gen Pract 2010;60:e423-33.

26. Stockley CJ, Reed MJ, Newby DE, et al. The utility of routine D-dimer measurement in syncope. Eur $\mathrm{J}$ Emerg Med 2009;16:256-60.

27. Dipaola F, Cucchi I, Filardo N, et al. Syncope as a symptom of non-massive pulmonary embolism: a case report. Intern Emerg Med 2006;1:167-70.

28. Reed MJ, Newby DE, Coull AJ, et al. Diagnostic and prognostic utility of troponin estimation in patients presenting with syncope: a prospective cohort study. Emerg Med J 2010;27:272-6.

29. Pfister R, Diedrichs $H$, Larbig R, et al. NT-pro-BNP for differential diagnosis in patients with syncope. Int J Cardiol 2009;133:51-4.

30. Pfister R, Hagemeister J, Esser S, et al. NT-pro-BNP for diagnostic and prognostic evaluation in patients hospitalized for syncope. Int J Cardiol 2012;155(2): 268-72.

31. Costantino G, Solbiati M, Pisano G, et al. NT-proBNP for differential diagnosis in patients with syncope. Int J Cardiol 2009;137:298-9.

32. Costantino G, Solbiati M, Sagone A, et al. Time course of B-type natriuretic peptides changes after ventricular fibrillation: relationships with cardiac syncope. Int J Cardiol 2011;153:333-5. 